\title{
INTRODUCTION
}

\section{Mercury on the Rise}

\author{
MICHAEL S. BANK
}

Mercury science is a rapidly growing interdisciplinary field and touches on nearly all academic and scientific disciplines, including biogeochemistry, economics, sociology, public health, decision sciences, physics, global change, and mathematics. Only recently have scientists really begun to establish more holistic approaches to studying mercury pollution, including investigations that have furthered the integration of a multitiered approach, especially by using chemistry, biology, and human health sciences.

The study of mercury pollution has contributed a variety of domestic and international policies related to the management of this ubiquitous contaminant. The target audience for this book is graduate and undergraduate students, natural resource managers, and technical scientists. The book focuses on integrating the diverse sciences involved in the process of mercury cycling in the environment from the atmosphere, through terrestrial and aquatic food webs, and in human populations to help the reader develop a more holistic perspective on this important environmental pollution topic.

The original idea for the book was developed at a conference in 2004, after an associate of the University of California Press who had viewed my oral presentation suggested that I consider writing a book on mercury pollution. After some investigating, I soon realized that although there were strong volumes on mercury pollution, none of them had a solid focus on aspects related to human dimensions and new topics such as advances in mercury isotope chemistry, and that current public health summaries were not readily available in the literature. This book largely stems from my desire to impart knowledge from worldwide experts on their areas of expertise and to disseminate the most current scientific information available about mercury.

The book has four parts: (I) mercury cycling in the environment: an introduction; (II) methods for research, monitoring, and analysis; (III) mercury in terrestrial and aquatic environments; and part (IV) toxicology, humans, policy, and risk analysis.

Part I, "Mercury Cycling in the Environment: An Introduction," serves as a basic introduction to the book. Chapter 1 focuses on sources, fate, and transport of mercury in the environment as a global problem and provides the reader with the critical background information on mercury pollution. Chapter 2 discusses historical and industrial uses of mercury in the environment, with a focus on ancient civilizations. The use of mercury by ancient civilizations has not received much attention, and this chapter describes mercury as a utility of human societies.

Part II, "Methods for Research, Monitoring, and Analysis," is dedicated to summarizing and highlighting recent advances in the study methods used in mercury investigations. Recent advances in the analytical methods used to measure mercury in the environment are discussed in Chapter 3. Because these methods are advancing rather quickly in the field, this chapter will be an important source for students, chemists, and laboratory scientists. Chapter 4 focuses specifically on mercury isotope fractionation and the use and application of mercury isotopes in source apportionment research and in determining biogeochemical pathways of mercury in the environment. Chapter 5 is devoted to the atmospheric chemistry and modeling of mercury. This sole atmospheric deposition chapter discusses, in detail, the reactions, behavior, and chemical properties of mercury in the earth's atmosphere and the role of scale and uncertainty assessments and their collective applications to monitoring, research, and policy. The chapter concludes by summarizing future challenges for mercury atmospheric deposition research. Chapter 6 focuses on indicators of environmental changes in mercury contamination in different ecosystem compartments and discusses the need for a national mercury monitoring 
network. This chapter discusses measurement approaches from the atmosphere to different wildlife indicator species that inhabit freshwater, terrestrial, and coastal ecosystems. The indicators identified in this chapter involve measurements made at several spatial and temporal scales and were selected to provide the best information to policymakers and other stakeholders and with regard to identifying the reasons and rates of change in mercury concentrations.

Part III, "Mercury in Terrestrial and Aquatic Environments," includes four chapters that focus on mercury in soils, forested watersheds, freshwater ecosystems, and marine environments. Chapter 7 summarizes the current knowledge about mercury in soils, which is critical to our understanding of the accumulation and loss of mercury in the environment and outlines the relationships between kinetics, climate, vegetation, disturbances, soil chemistry, and mercury speciation. Chapter 8 goes beyond soils and discusses mercury in forested watersheds. In this chapter, the authors review and synthesize information about mercury in terrestrial landscapes and describe how total mercury and methylmercury move through forested catchments. The authors also discuss, in detail, the role and effects of disturbance (forest harvesting, urbanization, etc.) on total mercury and methylmercury fluxes and their sensitivity to changes in mercury emission rates, land-use practices, and climate. Chapter 9 deals with mercury in freshwater ecosystems. In this chapter, the authors describe biotic and abiotic mechanisms that govern mercury methylation, bioaccumulation, and trophic transfer in a wide array of aquatic food webs and ecosystems, including natural lakes and ponds, reservoirs, wetlands, and rivers. The authors provide examples of mercury cycling and bioaccumulation by examining case studies from the Everglades, Adirondack mountain lakes, man-made reservoirs, large lakes such as Lake Michigan, and the Nyanza Superfund site on the Sudbury River in Massachusetts. Chapter 10 is a comprehensive summary of mercury in the marine environment, with regard to human and environmental health concerns. In this chapter the authors discuss the source of mercury in marine ecosystems, methylation of mercury, and bioaccumulation and biomagnification in marine food webs.

Part IV, "Toxicology, Risk Analysis, Humans, and Policy," includes five chapters that discuss and summarize the recent advances in each of these important disciplines. Chapter 11 focuses on the ecotoxicology of mercury, primarily as methylmercury, in wildlife such as fish, amphibians, birds, and mammals. Chapters 12 through 15 are dedicated to risk assessment, public health, and environmental justice. These chapters report on a variety of topics, including risk assessment models, human exposure routes of the different mercury species, and fish consumption patterns related to socioeconomic dynamics. Chapter 16 integrates many scientific aspects discussed throughout the book and summarizes mercury policy initiatives in the context of both environmental and human health.

The field of mercury science is tremendous in scope and scale and I hope this book serves as a preliminary, introductory step for students, researchers and scientists to develop a further interest and understanding of mercury pollution and cycling in the environment. 